Journal of Contemporary Indonesian Art

Volume 1 No.1 - April 2015.

JOURNAL of

CONTEMPORARY INDONESIAN ART Jurusan Seni Murni FSR ISI Yogyakarta ISSN: 2422-3394

\section{WACANA POSTMODERN \\ DALAM SENI RUPA KONTEMPORER INDONESIA}

\section{Oleh : I Gede Arya Sucitra}

Institusi: Institut Seni Indonesia Yogyakarta

Alamat: Jl. Parangtritis, KM. 6,5 Sewon Bantul Yogyakarta

email: boykbali@gmail.com

\section{ABSTRACT}

Artikel ini merupakan produksi teoritis mengenai konsep postmodern yang mendasari kelahiran konsepsi seni rupa kontemporer. Diperkuat dengan makin berkembangnya kecenderungan perupa muda di Indonesia yang mengolah kekuatan visual budaya tradisional dikombinasikan dengan kecenderungan estetika terkini. Akibatnya, karya-karya yang dihasilkan menjadi karya yang bersifat global namun masih menampakkan jejakjejak nilai tradisinya. Kajian teoritis pada artikel lebih lanjut akan dimulai melalui metode kajian pustaka.

Untuk itu akan dilakukan telaah analisis mengenai konsep estetika seni rupa kontemporer melalui studi literatur dari berbagai macam buku seni, tulisan para pemikir seni, dan pencipta seni. Pemaparan definisi dan pernyataan seni dalam artikel ini bertujuan untuk memetakan arah pemikiran seni rupa kontemporer dunia secara umum dan khususnya menelaah ranah penciptaan karya seni rupa kontemporer Indonesia.

Kata kunci: postmodern, seni rupa kontemporer, budaya tradisional

\section{ABSTRAK}

The Postmodern Paradigm in Contemporary Indonesian Art. This article is a theoretical production of the postmodern concept underlying conception of the birth of contemporary art. Reinforced by the growing tendency of young artists in Indonesia who cultivate the visual power of traditional culture combined with the latest aesthetic tendency. As a result, the works produced into works that are global, but still showing traces of the value of tradition.

Theoretical studies on more articles will be initiated through the method of literature review. The study will be conducted for the analysis of the aesthetic concept of contemporary art through the study of literature from a wide variety of art books, writing art thinkers, and creators of art. The exposure of definitions and statements of art in this article aims to map out the direction of thinking contemporary art world in general and in particular examine the realm of creation of works of contemporary art in Indonesia.

Keywords: postmodern, contemporary art, traditional culture 


\section{PENDAHULUAN}

The contemporary art world is nowadays being transformed by artists who combine influences from different cultural and aesthetic traditions into the multi-faceted selves manifested in their works (Green, 2005: 12-13).

Tulisan ini dikembangkan dari makin maraknya kecenderungan perupa muda di Indonesia yang mengolah kekuatan visual budaya tradisi dikombinasikan dengan kecenderungan estetika terkini. Akibatnya, karya-karya yang dihasilkan menjadi karya yang bersifat global namun masih menampakkan jejak-jejak nilai tradisinya. Di sisi lain adanya paradigma seni yang mengatakan bahwa seni rupa kontemporer yang kini hangat berkembang di atmosfer seni rupa dunia dikategorikan sebagai karya yang dihasilkan oleh paradigma postmodern (postmodernisme) sehingga beberapa pihak acap menyulih istilah kontemporer dengan postmodernisme (seni rupa kontemporer = seni rupa postmodernisme) (Saidi, 2008: 18).

Berpijak dari persoalan gagasan di atas maka dalam pembahasan artikel lebih lanjut akan dimulai melalui metode kajian pustaka. Untuk itu akan dilakukan telaah analisis mengenai konsep estetika seni rupa kontemporer melalui studi literatur dari berbagai macam buku seni, pandangan para penulis seni, kurator pameran seni rupa, pemikir seni hingga perupa kontemporer mengenai batasan, hingga ciri seni rupa kontemporer di Indonesia. Dengan demikian tujuan untuk membedah latar penciptaan dan pemikiran dari proses kreatif kehadiran karya-karya perupa kontemporer di Indonesia dapat dipahami.

Senyatanya banyak perupa muda di Indonesia yang berkarya dan berproses kreatif dalam atmosfer seni rupa kontemporer Indonesia dengan mengusung nilai-nilai tradisi melalui eksplorasi elemen- elemen budaya lokalnya seperti wayang, prasi (lontar), cerita rakyat, topeng, aksara lokal, tarian dan sebagainya dimana ia hidup dan berkembang yang tentunya telah dinegoisasikan dengan pengaruh-pengaruh ter-kini dan berbagai teknik seni modern. Dengan pemaparan mengenai definisi, paradigma seni rupa postmodern, latar problematika kelahiran seni rupa kontemporer dengan pembahasan nilai-nilai dan konsepsi karakter kekaryaan sebagai bagian areal dialektika estetik penciptaan karya perupa kontemporer.

\section{PEMBAHASAN}

\section{A. Gejala Postmodern dalam Seni Rupa} Paradigma postmodern sebagai latar konseptual yang dominan saat ini mengidentifikasi bahwa salah satu ciri seni rupa kontemporer adalah tingkat kepedulian yang tinggi terhadap realitas kehidupan masyarakat ketimbang mengurusi masalahmasalah estetika seni itu sendiri. Seni rupa kontemporer adalah seni yang cenderung membidik kepala (gagasan) dan hati (perasaan) daripada mata (visual). sumbernya?

Nicolas de Olieveira menjelaskan bahwa kemunculan instalasi ditandai oleh munculnya istilah ready mades untuk menamai karya Marcel Duchamp (Perancis Amerika) pada 1913, yakni Bicycle Wheel. Ide karya ini adalah menjadikan barang-barang jadi dalam realitas sebagaimana adanya menjadi karya seni yang dapat dipamerkan dalam galeri. Instalasi adalah karya yang merespon ruang dan dengan begitu, mengubah konsep galeri. Pada awal 1960-an juga dikenal istilah-istilah assemblage dan environment art yang dirujukkan pada bentuk seni instalasi. Olieveira selanjutnya mengatakan bahwa instalasi merupakan seni total (gesamtkunstwerk) yang memiliki sifat pertunjukan (theatricality) yang di dalamnya tercermin aspek-aspek futurism, 
dada, constructivism, dan Bauhaus programme (Saidi, 2008: 5).

Kompleksitas permasalahan istilah seni rupa kontemporer-postmodern memungkinkan para seniman mencari berbagai cara dan medium untuk merepresentasikannya. Dalam konteks ini berkarya rupa tidak hanya berkutat pada permasalahan teknik, melainkan bagaimana pula menyalurkan gagasan menyangkut berbagai persoalan tadi. Dengan demikian, sekali lagi bisa ditegaskan bahwa kata kontemporer yang dilekatkan pada frasa seni rupa bukan merupakan istilah yang merujuk pada sebuah aliran atau gaya berkesenian, melainkan hanya sebuah aktivitas berkesenian yang dianggap terkini pada setiap zaman oleh pengamat yang hidup pada setiap zaman bersangkutan. Di Barat sendiri, sebagai pihak pertama yang memunculkan istilah contemporary art, hal yang sama juga terjadi. Arthur Danto seperti yang dikutip Acep Iwan Saidi (2008: 18) mengatakan bahwa belum terbentuk definisi seni kontemporer dalam konteks 'gaya kontemporer'. Chris Barker (2004: 156-157) menyatakan bahwa konsep posmodern dapat dipahami sebagai berikut: (1) acultural style marked by intertextuality, irony, pastiche, genre blurring and bricolage; dan (2) a philosophical movement that rejects 'grandnarratives' (that is, universal explanations of human history and activity) in favour of irony and forms of local knowledge.

Di lain sisi Yasraf Amir Piliang (Saidi, 2008: 12-14) menjelaskan istilahistilah modernpostmodern dengan menunjukkan perbedaan perbedaannya sebagai berikut. (1) Modern - Postmodern: istilah ini mengacu pada waktu, era, zaman, dan semangat zaman. Postmodern bisa dikatakan sebagai waktu, era, zaman, dan semangat zaman setelah modern. (2) Modernitas - Postmodernitas: istilah ini mengacu pada kondisi, keadaan, situasi umum, realitas, dunia kehidupan (life world). Modernitas adalah sebuah kondisi, keadaan, situasi umum, realitas, dan dunia kehidupan (life world) yang memiliki ciri kemajuan (progres), integrasi, keterpusatan, kontinuitas, dan kebaruan; Postmodernitas adalah kondisi, keadaan, situasi umum, realitas, dan dunia kehidupan (life world) yang memiliki ciri nostalgia, pastiche, disintegrasi, fragmentasi, heterogenitas, dan decentering. (3) Modernisme - Postmodernisme: istilah ini mengacu pada gerakan (movement), gaya (style), ideologi, kecenderungan, metode, cara hidup, dan keyakinan. Modernisme adalah gerakan (movement), gaya (style), ideologi, kecenderungan, metode, cara hidup, dan keyakinan yang mengacu pada universalisme, internasionslisme, imperialisme, etnosetrisme, dan rasisme; Postmodernisme adalah gerakan (movement), gaya (style), ideologi, kecenderungan, metode, cara hidup, dan keyakinan yang mengacu pada pluralisme, dekonstruksionisme, multikulturalisme, poskolonialisme, dan feminisme.

Tampak dari pendefinisian di atas bahwa istilah modern berbanding lurus dengan modernitas dan modernisme. Istilahistilah ini kemudian bisa dikatakan berbanding terbalik dengan postmodern, postmodernitas, dan postmodernisme. Mengacu pada penjelasan dan pemosisian ini, seni rupa yang memiliki kecenderungan postmodern (postmodernisme) adalah seni rupa yang bisa dibedakan dengan seni rupa pada paradigma modern (modernisme).

John. A. Walker (Sumartono, 2003: 70) dalam bukunya Art ini the Age of Mass Media yang terkutip dalam tulisan Sumartono memaparkan bahwa ciri-ciri seni rupa postmodern tidak dapat dirumuskan secara pasti, tetapi beberapa ciri utamanya adalah (1) seni rupa postmodern mengakui adanya pluralitas gaya dan tidak ada satu pun gaya yang dominan, (2) sejarah dan tradisi 
masa lalu (termasuk sejarah modernisme sendiri),bisa dibangkitkan lagi, gaya-gaya lama bisa didaur ulang, demikian juga unsurunsur seni rupa masa lalu bisa dimanfaatkan, (3) seni rupa atas dan seni rupa bawah bisa dicampur, demikian juga seni rupa murni dan seni rupa komersial, (4) intertekstualitas lebih ditegaskan, intertekstualitas adalah istilah yang terutama digunakan dalam teori sastra untuk menjelaskan bahwa sebagian besar teks sastra berkaitan atau mengutip teks-teks sastra yang lain (intertekstualitas dalam seni rupa artinya adalah bahwa sebagian besar karya seni rupa berkaitan atau mengambil unsur unsur yang berasal dari karya-karya seni rupa yang lain).

Menelaah berbagai pemikiran dan perspektif seni yang berkembang seputaran seni kontemporer maka dapat dipahami pengertian seni rupa kontemporer bisa mencangkup wilayah yang sangat luas dengan berbagai kebudayaan yang melingkupi kehadirannya. Pembahasan atas topik kontemporer pada suatu karya seni dapat didudukan dalam konteks budaya yang melatarinya. Sebagaimana telah disinggung di awal, karya seni adalah produk budaya di mana para senimannya lahir dan berkarya. Selalu ada kaitan antara kehidupan para seniman dengan perilaku budaya setempat yang melahirkannya. Cita rasa estetik seni kontemporer menggandeng bentukbentuk tradisi, kebudayaan urban, teknologi modern hingga kebudayaan pop sebagai sumber inspirasi proses kreatif. Senada hal tersebut seperti yang disampaikan M. Dwi Marianto (2001: 192) sebagai berikut.

Bahkan seni kontemporer tidak ragu-ragu menggandeng seni tradisional. Sebab yang paling penting dalam seni kontemporer adalah bukan sesuatu atau elemen yang dipakai untuk berbicara melalui karya seni, tetapi bagaimana rangkaian dari elemen atau komponen-komponen yang diambil dari seni tradisional atau seni pramodern disampaikan. Rasa kekontemporeranlah yang berperan untuk presentasi seni kontemporer.

Sejalan dengan pemikiran Marianto di atas, pada titik tertentu membicarakan seni rupa kontemporer adalah membicarakan kebebasan ekspresi. Seniman berada di zona kebebasan dimana karya yang hadir tidak harus selalu terikat oleh konvensi-konvensi penciptaan, bersifat transmedia, mencari kebaruan-kebaruan yang aneh dan unik, bebas dari kebutuhan maupun fungsi-fungsi duniawi. Seperti yang disampaikan Julian Stallabrass (2004:1) dalam Contemporary Art: A Very Short Introduction menyatakan sebagai berikut.

Contemporary art seems to exist in a zone of freedom, set apart from the mundane and functional character of everyday life, and from its rules and conventions. In that rone, alongside quieter contemplation and intellectual play, there flourishes a strange mix of carnival novelty, barbaric transgressions of morals, and offences against systems of belief.

Seni kontemporer melalui konsep postmodernisme mengakui dan menghargai pluralitas dan oleh sebab itu memberi peluang bagi masuknya nilai-nilai lokal dan tradisi bangsa manapun untuk masuk kedalamnya. Postmodernisme adalah pintu yang terbuka lebar untuk masuknya tradisi dan nilai-nilai lokal. Barker (2004: 157) mengatakan ...the postmodern can be read as the democratization of culture and of new individual and political possibilities.

Pembahasan mengenai konsepsi seni kontemporer pada suatu karya seni seringkali didudukan dalam konteks budaya yang melatarinya. Sebagaimana telah disinggung di awal, karya seni adalah produk budaya di mana para senimannya lahir dan berkarya. Selalu ada kaitan 
antara kehidupan para seniman dengan perilaku budaya setempat yang melahirkannya. Hubungan kontekstualitas ini sesuai dengan pemikiran I Made Bandem (2006: 5) yang mengatakan.

Seni apapun bentuk dan jenisnya, baik sederhana maupun rumit, saya kira selalu memiliki sebuah konsep, misalnya konsep keindahan. Keindahan sebuah seni dapat dilihat lewat tekstur (teks) dan masih mempunyai hubungan erat dengan fenomena kehidupan (konteks). Konsep dalam seni dapat tercermin dalam ide, atau tema, yang kemudian menjadi isi atau esensi sebuah karya seni. Pelukis-pelukis Bali atau para koreografer tari Bali yang berkeseniannya berdasarkan konsep ngayah (pengabdian atau devotion) kebanyakan mengambil tema dari konsepsi kehidupan masyarakat Bali. Tema keharmonisan seperti Rwa Bhinneda, Tri Hita Karana, ataupun konsepsi lainnya mendominasi tema-tema karya seni Bali.

Dalam hal seni rupa, perupa kontemporer juga banyak mengeksplorasi nilai-nilai lokal ke dalam karyanya seperti budaya seni wayang, batik, topeng, patung, tari-tarian tradisional, hingga legenda/mitos mitologi lokal.

\section{B. Wacana Seni Rupa Kontemporer Indonesia}

Dalam konteks seni rupa Indonesia yang aspek kesejarahannya tidak tertata dengan mantap, persoalan mendefinisikan dan pembagian ruang modern-kontemporer semakin kompleks. Indonesia adalah negeri yang hidup dalam abad ke-21 sekaligus dimana tradisi, modernitas, postmodernitas, takhayul, mistik, dan lainlain berbaur dalam aktivitas keseharian (Saidi, 2008: 10). Hal yang terjadi sepanjang perjalanan berbagai macam tradisi tersebut di atas adalah dialog. Dialog ini yang kemudian memunculkan berbagai macam kompromi negosiasi pembaruan.

Kemunculan sebuah karya baru yang semangat pendobrakannya sangat radikal sekalipun, tetap dimotivasi oleh kecenderungan dominan karya sebelumnya. Sejarah kesenian sebenarnya merupakan pergerakan dari mitos ke mitos. Sebuah karya baru muncul meruntuhkan kecenderungan zaman sebelumnya yang telah menjadi mitos. Selanjutnya, dalam perjalanan waktu, secara otoregulatif karya baru yang dikatakan melakukan pendobrakan itu kembali akan menjadi mitos sampai ada karya lain yang 'meruntuhkannya'. Demikian dialektika itu berjalan terus-menerus dalam spektrum sejarah. Namun demikian bukan berarti aspekaspek estetika yang melingkupi karya seni yang berkembang di Indonesia tidak dapat ditelaah dan dipetakan. Menyoal kembali pertanyaan awal di atas, apakah seni rupa kontemporer, apa yang memperbandingkannya dengan istilah sebelumnya yakni seni rupa modern.

Seni kontemporer adalah terjemahan dari contemporary art. Kata contemporary/ kontemporer berasal dari dua kata Latin yaitu com atau con, dan tempus atau tempor. Com atau con adalah awalan yang berarti 'dengan' atau 'bersama'. Sedang kata tempo atau tempor berasal dari bahasa Latin tempus atau temporis yang artinya 'waktu'. Misalnya dapat dilihat pada kata temporer terjemahan temporary, artinya for the time being atau sekarang ini. Kata kontemporer berasal dari contemporary, kalau dipilah-pilah menjadi contempor-ary. Con artinya sama-sama atau bersamaan, tempor artinya waktu, sedang ary adalah akhiran dari Bahasa Inggris yang membentuk kata benda atau kata sifat, atau yang artinya 'sama-sama' atau 'bersamaan', dan tempus atau temporus berarti 'waktu'. 
Contemporary/ kontemporer mengartikan apa-apa atau mereka yang hidup ada masa yang bersamaan (Marianto, 2001: 189).

Caroline Turner, peneliti seni rupa Asia Pasifik, mantan direktur artistik Triennale Seni Rupa Kontemporer AsiaPasifik Queensland Art Gallery, menganggap bahwa perkembangan seni rupa kontemporer adalah suatu hasil tradisi, dari berbagai ragam pertemuan kultural yang bersifat historis, hasil dari konfrontasi dengan dunia Barat modern, serta interaksi yang dihasilkan dan yang terus mengalami percepatan akibat berbagai perubahan bidang ekonomi, teknologi serta informasi mutakhir yang telah mendorong kemajuan dunia menuju apa yang disebut kini sebagai kebudayaan 'global' (Zaelani, 2007: 7). Jadi yang dimaksudkan dengan seni kontemporer di sini adalah karya seni yang ide dan pembahasannya dibentuk dan dipengaruhi sekaligus merefleksi kondisi yang diwarnai dengan keadaan zaman ini tempat 'budaya global' menyeruak, yang menebarkan banyak pengaruh yang menjadi penyebab berbagai perubahan dan perkembangan.

Sebagai catatan, penjelasan Turner menimbang pada kesamaan pengalaman yang ia temui dalam beberapa perkembangan seni rupa kontemporer khususnya di kawasan Asia dan Pasifik, contoh yang bisa dilihat jelas pada penyelenggaraan Triennale di Brisbane. Penjelasan Turner, tentu juga berlaku bagi perkembangan seni rupa kontemporer Indonesia, yang dalam penyelenggaraan kegiatan Triennale sampai sekarang itu selalu menampilkan wakil senimannya. Mungkin, inilah salah satu cara pandang untuk mengenal perkembangan seni rupa kontemporer melalui perspektif (kepentingan) suatu kawasan (Asia-Pasifik). Sebenarnya, dalam sejarahnya, seni rupa kontemporer juga muncul akibat logika perkembangannya sendiri. Seni rupa kontemporer muncul dan tumbuh dalam logika perkembangan yang sama, yang jadi dasar perkembangan tradisi seni rupa modern itu sendiri, secara keseluruhan.

Sementara itu, Lyotard menyatakan bahwa kondisi postmodern bukan sejarah zaman,... namun mencakup pengetahuan lokal, plural dan pengetahuan yang heterogen khususnya dalam permainan bahasa. Lebih lanjutnya dikatakan,

For Lyotard, the postmodern condition is not a historical epoch or a set of institutional parameters but rather the condition of knowledge of post-industrial societies. While modern knowledge rests on its appeal to grand narratives, the postmodern condition involves an 'incredulity toward metanarratives' and embraces local, plural and heterogeneous knowledges that are specific to languagegames (Barker, 2004: 112).

Salah satu dimensi yang paling menonjol dewasa ini adalah perubahan yang terjadi secara serentak dalam berbagai aspek kehidupan dewasa ini yang semakin mengglobal. Masih menurut Caroline Turner, namun kali ini dalam tulisannya di katalog The Second Asia-Pacific Triennal of Contemporary Art tahun 1996, menurutnya seni kontemporer adalah seni yang merefleksi keadaan yang senantiasa berubah dari masyarakat kontemporer (Marianto, 2001: 190)

Guna mempertegas gambaran tentang apa yang dimaksud dengan seni kontemporer, kiranya layak dicermati pendapat Apinan Poshyananda dalam kutipan M. Dwi Marianto (2001: 191) yang mengatakan bahwa seni kontemporer harus dipandang dalam konteks tempat dan kondisi dari seni kontemporer yang bersangkutan. Keadaan di berbagai negara Asia dewasa ini sangat diwarnai dengan berbagai macam budaya hibrida, juga ditandai dengan situasi penuh konflik dalam berbagai suasana serba paradoksal. 
Di dunia seni rupa Indonesia sendiri kata kontemporer sebagai sebuah istilah digunakan lagi dalam sebuah pameran bertajuk 'Pameran Pertama Patung Kontemporer Indonesia’ pada tahun 1973. Kata kontemporer yang digunakan dalam tajuk pameran ini digagas G. Sidharta untuk menggantikan kata modern, awalnya bertajuk 'Pameran Pertama Patung Modern Indonesia'. Kata modern diganti dengan kontemporer karena pada saat itu karya yang dipamerkan masih banyak yang mencerminkan tradisi sehingga peserta dari Bandung mempertanyakan keabsahan penggunaan kata modern (Saidi: 2008, 18).

Sejauh ini persoalan yang sering muncul ialah ketika istilah kontemporer dikaitkan dengan wacana yang berkembang dalam dunia kesenian secara umum dan seni rupa itu sendiri secara khusus. Dalam ranah ini istilah seni rupa kontemporer sering dihubungkan dengan sebuah gejala seni rupa yang membedakan dirinya dari seni rupa sebelumnya, yakni seni rupa modern. Seni rupa kontemporer dikategorikan sebagai karya yang dihasilkan oleh paradigma postmodern (postmodernisme) sehingga beberapa pihak acap menyulih istilah kontemporer dengan postmodernisme (seni rupa kontemporer $=$ seni rupa postmodernisme).

Arthur Danto melalui bukunya After the End of Art dalam tulisan Acep Iwan Saidi (2008: 19) mengatakan bahwa istilah kontemporer pada contemporary art tidak sekedar berfungsi sebagai temporal sense. Seni rupa kontemporer, menurut Danto, adalah seni yang dihasilkan oleh struktur produksi yang belum pernah ada sebelumnya. Supaya seni rupa kontemporer tidak disamakan dengan berbagai aktivitas atau praktek seni rupa pada masa kini, Danto menyarankan bahwa seni rupa kontemporer bisa dipahami sebagai seni rupa yang memiliki kecenderungan postmodern.
Secara teoritis, umumnya perkembangan seni rupa kontemporer dipahami muncul sebagai suatu bentuk 'perlawanan', terhadap perkembangan seni yang mapan bersandar pada prinsip-prinsip Modernisme. Modernisme adalah keyakinan seni, bahkan bagi sebagian orang disebut juga sebagai 'ideologi', yang percaya pada logika kemajuan (progress) berdasar daya akal manusia. Tentu, prinsip Modernisme tak hanya dijalankan dalam bidang seni rupa saja, melainkan terutama justru berarti seluruh logika gerak kemajuan kemanusiaan secara keseluruhan ekspresi seni hanyalah bagian darinya. Prinsip Modernisme dalam seni mengandaikan adanya semacam 'semangat zaman' berlaku di beberapa periode, secara berbeda-beda, yang dipercaya membawa semangat penyelamatan nilai-nilai hidup kemanusiaan setiap zaman.

Kemunculan berbagai manifesto gaya seni rupa, dengan janji-janji bentuk kemajuan seni, sejak awal abad ke-19 hingga paruh pertama abad ke-20, adalah contoh dari praktek Modernisme. Setelah Perang Dunia ke-2 berakhir, khususnya setelah tahun 1960'an, gejala perkembangan seni rupa kontemporer mulai muncul. Bisa dikatakan bahwa seni rupa kontemporer adalah suatu bentuk perkembangan seni rupa dalam kelangsungan suatu tradisi seni rupa, yang disebut tradisi seni rupa modern. Tradisi seni rupa modern, seperti halnya 'seni tradisi', adalah adat cara kebiasaan seni yang dijalankan secara menerus, turuntemurun, berdasar pada konvensi nilai-nilai tertentu yang diakui secara bersama (Zaelani, 2007: 6).

According to the most fashionable theorizing, art in the 1980s is involved in a kind of endlessly prolonged Postmodernist end-game, unable either to continue the tradition or to establish a living relation with the masters. Art, the most influential theorists say, may appropriate from that old master 
tradition, which it is powerless either to contribute to or to continue. This issue has been much discussed in the now somewhat academic accounts of Postmodernism (Bann dan Alien, 1991: 68).

Ada perbedaan yang jelas antara estetika Modernis yang memperjuangkan universalisme,dengan Barat sebagai penentu cita rasa seni rupa dunia, di sisi lainnya estetika Postmodernis merayakan 'perbedaan', menaruh perhatian pada hal-hal yang khusus atau spesifik. Bila kaum modernis mencampakkan masa lampau demi inovasi-inovasi individual, kaum postmodernis cenderung meminjam masa lampau dan merasa tertantang untuk memposisikan informasiinformasi lama ke dalam konteks-konteks baru. Dibandingkan kaum Modernis, kaum Postmodernis cenderung eklektik dalam menggunakan media dan mereka dengan bebas menggabungkan bentuk-bentuk visual, teknikteknik, dan inspirasi dan berbagai macam sumber. Banyak di antaranya yang berasal dari budaya pop (Sumartono; 2003: 69). Postmodern culture is often argued to be a more visual culture than previously encountered and is connected to a general aestheticization of everyday life. It is also distinguished by a blurring of modern historical, aesthetic and cultural boundaries, including those between culture and art, high and low culture, commerce and art, culture and commerce (Barker, 2004: 157). Budaya pop atau budaya kemudaan ditandai oleh penonjolan kebebasan, imajinasi, eksperimentasi dan keberanian besar untuk mengejar impian lewat petualangan baik fisik maupun mental. Dalam segala bentuk dan manifestasinya musik, komik, film, cerita/novel pop, dan gaya penampilanbudaya kemudaan mendewakan kemudaan-usia muda, rasa muda, semangat muda, gaya muda, dan perilaku kawula muda (Hardjana, 1993: 16).
Di dunia Barat, pencampuran budaya memberikan kontribusi berbagai jenis dunia dengan posisi individu yang kompleks. Karena tidak searah, tidak adanya petunjuk yang mutlak dalam memaksakan estetika tunggal yang ideal, globalisasi pada tingkat politik dan ekonomi akan memperluas kapasitas kita untuk menerima jumlah yang tidak terbatas pada bahasa individu di tingkat budaya. Seni kontemporer akan tidak lagi dibaca dalam kerangka kritis yang ditetapkan oleh Greenberg. Sebaliknya kerangka kerja baru akan muncul dalam menanggapi fenomena artis multibudaya yang membawa dunia mereka sendiri dalam diri mereka seperti dalam diaspora, dan karya seni yang mengandung modus pemikiran yang berbeda serta konfigurasi diri. Seperti yang dinyatakan oleh Denise Green (2005: 30) dalam Metonymy in Contemporary Art: A New Paradigm:

In the West, this mixing of cultures contributes to a different kind of world with complex individual positions. Because there is no one direction, no absolute compass with which to impose a single aesthetic ideal, globalism at the political and economic level will extend our capacity to accept an unlimited number of individual languages at the cultural level. Today, this is already understood and discussed in other fields such as anthropology, literature, filmmaking, music and cross-cultural psychology. Contemporary art will no longer be read within the critical framework established by Greenberg. Instead new frameworks will emerge in response to the phenomenon of multicultural artists who carry their own world within themselves as in a diaspora, and whose art works contain different modes of thinking and configurations of the self.

Disisi lain ada pandangan yang lebih spesifik menyoal aspek estetik dari seni rupa kontemporer Indonesia yang digagas FX. 
Harsono, seorang perupa dan pemikir seni. Alumnus STSRI “ASRI” yang terlibat dalam gerakan GSRB 1975 dan hingga kini masih aktif berkarya seni dan melakukan penulisan seni rupa ini memiliki pandangan tersendiri mengenai definisi seni rupa kontemporer Indonesia yang berhasrat menunjukkan kepribadian yang khas dari fenomena seni rupa kontemporer yang berkembang di negeri ini. Ciri-ciri Seni Rupa Kontemporer Indonesia dalam analisis FX. Harsono (1992: 71-73) antara lain sebagai berikut.

(1) Konsep Estetik, yaitu: (a) Nonliris, bahwa penciptaan kesenian bukan hanya transformasi pengalaman estetik dan emosi seniman ke dalam dunia imajiner, tetapi sebuah ketja seni yang berusaha menghadirkan kekongkretan atau keaktualan. Bila lirisisme berusaha menggambarkan suatu keadaan dalam kanvas, non-liris berusaha menghadirkan benda secara nyata sebagai ungkapan karya seni. (b) Penolakkan terhadap pengkategorian penciptaan karya seni berdasarkan keahlian dan batasan dalam pengertian seni murni, misalnya seni lukis, seni patung, atau seni grafis. Berarti pula penolakan terhadap prinsip estetika seni rupa tinggi atau bigh art yang lahir pada masa Renaissance. Seni Rupa Indonesia Kontemporer berusaha memperkenalkan idiomnya sendiri, dengan mencoba mengacu pada situasi dan kondisi sosial, politik, ekonomi, dan kebudayaan Indonesia. (c) Penolakan terhadap universalisme, yang merupakan penolakan terhadap kegandrungan pemikiran bahwa sejarah seni rupa Indonesia berada di dalam alur sejarah seni rupa modem yang mengacu pada mitos Eropa dan Amerika. Artinya, bahwa kesenian kontemporer Indonesia mempunyai alur sejarah dan nilai-nilai estetika sendiri. (d) Nilai estetik bukan satusatunya nilai yang terpenting dalam penciptaan karya seni, tetapi masih ada nilai- nilai lain yang lebih penting, misalnya nilai kemanusiaan atau nilai sosial yang menempatkan fungsi sosial sebagai salah satu nilai yang penting, dengan tujuan sebuah karya seni mampu menciptakan kesadaran baru bagi masyarakat. (e) Penilaian suatu karya seni tidak selalu pada hasil akhir dari karya seni, tetapi proses penciptaan menjadi penting, karena interaksi antara seniman dan masyarakat, atau antara seniman dan seniman lain dalam setiap proses penciptaan terkandung nilainilai positif bagi kedua belah pihak, yang berupa kesadaran baru, pengalaman baru, dan nilainilai baru. (f) Pluralisme dalam perkembangan seni rupa merupakan suatu perjalanan yang sehat dan sah, pluralisme ini dilandasi sikap domokratis dan penolakan terhadap dominasi satu nilai.

(2) Proses Penciptaan, meliputi: (a) Sumber ide penciptaan tidak selalu lahir dari pengalaman estetik atau eksplorasi rasa estetik dan perenungan dari dunia dalam seorang seniman bersifat individual dan subtil, di mana semuanya itu merupakan legitimasi terhadap elitisme di dalam penciptaan kesenian, namun menempatkan kesenian sebagai bagian yang integral dengan kehidupan lain sehingga seni rupa merupakan bagian hidup sehari-hari. (b) Ide penciptaan tidak selalu muncul dari intuisiintuisi dan emosi semata, tetapi bisa bersumber pada ide serta konsep yang sering kali dipikirkan terlebih dahulu. (c) Proses penciptaan bersifat partisipatoris antara seniman dengan masyarakat, atau antara beberapa seniman secara bersama-sama. Dari proses kerja ini, maka interaksi antara mereka menghasilkan suatu nilai berbeda dan mempunyai arti penting dalam penilaian karya seni. (d) Proses penciptaan tidak lagi terpaku pada dogma seni murni, di mana seniman harus menciptakan dan mengerjakan seluruh kegiatan tersebut 
secara sendiri. Partisipasi dan kerja orang lain dalam proses penciptaan adalah sah.

(3) Teknik Penciptaan yang meninggalkan teknik konvensional. Pengalaman dan penjelajahan terhadap cara berkarya yang baru, baik dalam menggali pengalaman estetik maupun teknis dalam mengekspresikan karya seni, sehingga menghasilkan teknik-teknik baru antara lain:

(a) Teknik merakit atau menginstal, mengelas, menganyam, atau teknik-teknik lain yang tidak selalu mengandalkan craftmanship yang tinggi, merupakan teknik mencipta yang lazim dipakai. (b) Meninggalkan media ekspresi yang konvensional, seperti misalnya seni lukis, seni patung, seni grafis dan sebagainya, sehingga sulit untuk dikategorikan dalam disiplin seni rupa yang konvensional, karyakarya kontemporer disebut sebagai seni rupa saja. (c) Menggabungkan beberapa media penciptaan menjadi satu, sehingga penciptaan seni rupa bersifat multimedia. (d) Pengertian pameran dan cara mepresentasikan tidak terikat dengan cara presentasi yang konvensional, pengertian dan batasan ruang pamer lebih fleksible, ruang pamer tidak selalu berarti gedung, tetapi bisa juga alam, komunitas masyarakat, tempat-tempat umum. (e) Penjelajahan terhadap media baru yang memanfaatkan teknologi modern, seperti misalnya komputer, video, atau slide adalah sah sebagai suatu upaya untuk menemukan suatu media ungkap seni rupa. (f) Memadukan antara gerak, suara, dan rekaman gambar hidup atau video adalah sah sebagai upaya untuk mencari idiom baru dalam mengekspresikan suatu ide atau konsep penciptaan karya seni rupa.

(4) Orientasi Berkarya, meliputi: (a) Masalah politik, sosial, ekonomi, dan kebudayaan sahsebagai orientasi dalam mencari sumber ide. (b) Keperdulian dalam masalah sosial, kemiskinan, dan bersifat kontekstual. (c) Sikap individualndalam penciptaan pada beberapa seniman mulai berkurang dan menjadi bersifat partisipatoris. (d) Memakai tradisi dan bentuk-bentuk tradisi sebagai bahasa simbol terhadap permasalahan kebudayaan, dan bukan hanya sebagai upaya untuk mencari identitas ke Indonesia secara dangkal. (e) Idiom kebudayaan urban dan kebudayaan pop adalah cermin dari keterlibatan dan rasa tanggung jawab sosial seorang seniman yang hidup dalam kebudayaan kota saat ini.

Memusatkan perhatian pada karya seni kontemporer sebenarnya bisa pula bersandar pada satu pandangan bahwa karya dengan lintas-media dengan lintas-mashab dan lintas-wacana kini secara metaforis menggambarkan keadaan zaman globalisasi ini, tempat perkembangan teknologi informasi ternyata meruntuhkan berbagai batasan konvensional. Batas-batas nasional, sosial-budaya, dan sebagainya retak dan gugur dengan sendirinya (Marianto, 2001: 193).

\section{KESIMPULAN}

Melalui telaah wacana dari berbagai studi literatur mengenai konsep postmodern dan kaitannya dalam seni rupa kontemporer, membantu kita untuk melihat berbagai kecenderungan pemikiran mengenai seni rupa kontemporer. Seni kontemporer melalui konsep postmodernisme mengakui dan menghargai pluralitas dan oleh sebab itu memberi peluang bagi masuknya nilainilai lokal dan tradisi bangsa manapun untuk masuk kedalamnya. Imbasnya, penciptaan karya seni rupa kontemporer oleh perupa generasi muda yang berbasis pada pengenalan, pemahaman dan penerapan kearifan konsep-konsep nilai tradisi dalam pendekatan estetika yang lebih segar pada kekaryaan, tentu membuka harapan bahwa ketakutan budaya global akan makin 
menggilas, menggerus dan perlahan sirnanya seni-seni tradisi sebagai bagian penting penjaga nilai-nilai tradisilokalitas akan dapat dijaga dan dipertahankan. Konsepsikonsepsi lokal tersebut biasanya diangkat oleh para seniman sebagai isi atau tema pada karya seni rupa, seni pertunjukan dan seni cinematografi yang kemudian menyebabkan karya-karya itu sangat beragam bentuk dan gayanya.

Spirit seni kontemporer melalui konsep postmodernisme memberikan perspektif baru, kebebasan dalam memandang kebudayaan serta mengolahnya dalam perspektif personal. Postmodernisme adalah pintu yang terbuka lebar untuk masuknya tradisi dan nilai-nilai lokal.

Dengan demikian pembangunan karakter atas kebudayaan sendiri melalui pendekatan kearifan lokal beserta nilai-nilai tradisinya menjadi 'patner estetik' landasan penciptaan seni yang akan membuka gerbang kreativitas berkompetisi secara luas dan global di ruang estetika dunia seni rupa kontemporer.

\section{DAFTAR PUSTAKA}

\section{Jurnal}

Hardjana, Andre. 1993. "Kecenderungan Masyarakat di Masa Datang Dalam Konteks Kebudayaan". SENI Jurnal Pengetabuan dan Penciptaan Seni, III/01, Januari 1993, Yogyakarta: BP ISI Yogyakarta.

Harsono, FX. 1992. "Perkembangan Seni Rupa Kontemporer di Indonesia: Tinjauan Problematik". SENI Jurnal Pengetahuan dan Penciptaan Seni, II/03, Juli 1992. Yogyakarta: BP ISI Yogyakarta.

Sumartono. 2003. "Estetika Multikulturalis dan Seni Rupa Indonesia." Jurnal Ekspresi, Jurnal Lembaga Penelitian ISI Yogyakarta, Vol.7/03, 2003.

\section{Buku}

Bandem, I Made. 2006. "Metode Penelitian Seni", Disampaikan dalam Lokakarya Pengembangan Metodologi Penelitian, Perancangan/Penciptaan Seni dan latihan Penyusunan Proposal. Yogyakarta: LP ISI.

Bann, Stephen and William Alien. 1991. Interpreting Contemporary Art. London: Reaktion Books Ltd.

Barker, Chris. 2004. The Sage Dictionary of Cultural Studies. London: Sage Publication Ltd.

Green, Denise. 2005. Metonymy in Contemporary Art: A New Paradigm. United States: University of Minnesota Press.

Marianto, M. Dwi. 2001. "Gelagat Yogyakarta Menjelang Millenium Ketiga", dalam Outlet: Yogya dalam Peta Seni Rupa Kontemporer Indonesia. Yoyakarta: Yayasan Seni Cemeti.

Saidi, Acep Iwan. 2008. Narasi Simbolik Seni Rupa Kontemporer Indonesia. Yogyakarta: Isacbook.

Stallabrass, Julian. 2004. Contemporary Art: A $V$ ery Short Introduction. New York: Oxford University Press.

\section{Katalog}

Zaelani, Rizki A. 2007. "Common Grounds: A Glimpse of Indonesian Contemporary Art', dalam Katalog Pameran Seni Rupa Kontemporer Indonesia, Galeri Nasional, 13-19 April 2007. 